\title{
VARIEDAD ESTRÓFICA Y CONTRAPUNTO RÍTMICO EN NUEVAS CANCIONES DE ANTONIO MACHADO
}

\section{STANZAIC VARIETY AND RHYTHMIC COUNTER- POINTING IN ANTONIO MACHADO'S NUEVAS CANCIONES}

\author{
Jesús Andrés Esteban Vergara \\ IES Duques de Nájera (Logroño)
}

\begin{abstract}
Resumen: Nuevas canciones es un libro de composición intermitente que recoge poemas de diversos temas y tonos escritos a lo largo de un amplio periodo de la vida del autor (de 1917 a 1936). El objetivo de este trabajo es mostrar que, bajo la apariencia de heterogeneidad, el libro mantiene la unidad y la coherencia, y que ambas derivan de un programa intencionado en sus usos métricos. Este programa, que lo es tanto poético como ideológico y ético, tiene su base en la reducción del repertorio de metros y de estrofas del autor, a la vez que éste explota al máximo sus posibilidades combinatorias siguiendo lo que hemos denominado "ley de la variación estrófica" y "ley del contrapunto rítmico".
\end{abstract}

Palabras clave: Antonio Machado, Nuevas canciones, ritmo, variedad estrófica, contrapunto.

Abstract: Nuevas canciones is an occasionally composed book that brings together poems with different themes and tones written over an extended period of the author's life (from 1917 to 1936). The aim of this study is to show that, under the guise of heterogeneity, the book does maintain unity and coherence which 
are the result of a programmatic approach to metrics. This program, which is both poetic, ideological and ethical, is based on the reduction of the author's range of meters and stanzas, exploiting at the same time their full combinatorial potential, following what we have called the law of stanzaic variety and the law of rhythmic counterpointing.

Key words: Antonio Machado, Nuevas canciones, rhythm, stanzaic variety, counterpoint. 


\section{Contexto: lo popular en Machado}

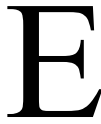

N Nuevas canciones Antonio Machado muestra definitivamente su amor por la poesía tradicional y culmina, a partir de ésta, una muy personal ideología sobre la base de que la verdadera poesía es la que hace el pueblo, en la conocida expresión de Juan de Mairena. Este amor de Machado por lo popular tiene hondas raíces familiares: Antonio Machado padre, Demófilo, había sido un gran folclorista y sus Cantes flamencos ${ }^{1}$ resultan de una gran importancia como hito en este camino hacia lo popular que Antonio hijo irá completando con su propia formación en la Institución Libre de Enseñanza, la lectura de los clásicos, la antología de poesía popular que realizó en su cuaderno Los complementarios o su amplio conocimiento de los cancioneros que fueron apareciendo desde finales del siglo XIX. A todo esto hay que sumar lo que la propia evolución poética de Machado había ido vertiendo sobre el venero de lo popular, desde Soledades (1899-1907) hasta la aparición de Nuevas canciones (1917-1930), pasando por Campos de Castilla (1907-1917).

Nuevas canciones se publicó en Madrid en 1924 recogiendo, según las fechas que seguían al título, poemas de 1917 a 1920. El libro se irá alargando en sucesivas reediciones: entra en las Poesías completas de 1928 con algunos cambios respecto a la primera edición (supresiones y añadidos), no varía en la edición de 1933 y añade un nuevo poema (A Julio Castro) en 1936. El libro, así, es acorde al modo intermitente de la composición del

\footnotetext{
${ }^{1}$ Puede consultarse esta obra, la más singular entre las que Antonio MACHADO y ÁLVAREZ realizó sobre el folclore andaluz, en Cantes flamencos recogidos y anotados por Antonio Machado y Álvarez (Demófilo). Barcelona: DVD Ediciones, Los cinco elementos, 1998. La presentación la hace Antonio Gil, quien destaca la influencia del padre sobre sus hijos Manuel y Antonio, cuyo interés por la cultura popular quedará reflejado ya en toda su obra.
} 
autor, recoge poemas de diversas fechas y diverso tono, algunos incluso publicados en revistas antes de 1917, y se extiende a lo largo de las estancias del autor en Baeza y, a partir de 1919, en Segovia. Según el estudio de Oreste Macrí ${ }^{2}$ para su edición de la obra completa de Antonio Machado, el libro puede resumirse como la "mezcla de clasicismo y folclore", considerando estos dos términos siempre dentro de la personal búsqueda y la hondura del autor. A lo largo del libro nos iremos encontrando de una forma heterogénea con los temas conocidos del recuerdo, la búsqueda del tú esencial, la soledad, la confesión íntima a modo de diario, el lirismo del sueño, el paisaje andaluz -sencillo, en breves apuntes, incluso con humor- y la rememoración emocionada del paisaje castellano. No faltarán los poemas de elogio (a Baroja, Azorín, Valle-Inclán, Francisco de Grandmontagne, Eugenio D’Ors, Julio Castro, las bodas de Francisco de Icaza, Francisco Romero, el escultor Emilio Barral) y, junto a todo ello, por supuesto, la línea aforística de los Proverbios y cantares (profundización de los que ya habían aparecido en Campos de Castilla) y, finalmente, la particularidad de los sonetos. Si el amor por el folclore está siempre presente en Machado, es ahora cuando cuaja y se convierte en la meta, la dirección y en el camino, según Manuel Alvar ${ }^{3}$, para quien la clave del libro está en la tierra soriana y en la belleza de los viejos cancioneros. Para Macrí, en cambio, las fechas de las composiciones no dejarían lugar a dudas: indican que primero son las canciones de Andalucía (Apuntes, Hacia tierra baja) y que luego éstas se amplían con las Canciones de varias tierras, y todas, a su vez, preceden a las Canciones del alto Duero (publicadas en 1922) y a las Viejas canciones (1928), que son las canciones que rememoran el paisaje castellano soriano. Es el mito de lo andaluz y la copla lo que lleva al autor hacia el folclore: pero no a la copla colorista, al flamenco como artificio, sino a una estilización mítica y elemental, de gran fuerza (cante jondo primitivo y apocalíptico), que anuncia y anticipa la obra de Lorca en su Romancero.

${ }^{2}$ Machado, Antonio: Poesía y prosa. Tomo I. Introducción. Edición crítica de Oreste Macrí. Madrid: Clásicos Castellanos, Ed. Espasa Calpe, 1989, pp. 185 y ss.

${ }^{3}$ Machado, Antonio: Poesías completas. Edición de Manuel Alvar. Madrid: Ed. Espasa Calpe, Colección Austral, 2009, 48º edición, introducción, p. 46. 
Efectivamente la forma peculiar de la canción y el ahondamiento en la vena popular avanzan en Nuevas canciones de una forma tan personal y tan intencionada que es evidente que el libro termina por parecernos rico, unitario y coherente frente a lo que, a primera vista, puede sugerir intermitencia e irregularidad. Tomás Navarro Tomás, en "La versificación de Antonio Machado" ", explica claramente lo que pasa con Nuevas canciones:

No obstante la progresiva reducción del repertorio de sus metros y la relativa escasez de sus tipos de estrofas, la impresión que se recoge del conjunto de la versificación de Machado es de extraordinaria variedad. Hay un continuo y movido cambio de efectos rítmicos aun entre sus formas de apariencia más semejante. Sin tratar de introducir innovaciones, su procedimiento consistió en someter a constante reelaboración los modelos más corrientes y en combinar con libertad los elementos métricos de cada composición. ${ }^{5}$

Para Navarro Tomás es la estrofa el elemento al que Machado atiende de forma primordial en su poesía. En nuestra opinión, Machado encuentra una muy personal libertad métrica en la depuración, el ahondamiento y la reelaboración de las formas más tradicionales de nuestra poesía, las que tienen su base en las canciones castellanas y andaluzas, en la copla y la soleá. Pero, de forma paralela, el autor reelabora también la tradición del verso largo: el endecasílabo de las silvas y -por primera vez en su obra- del soneto. El libro funde así los elementos clásicos y populares. El estudio detallado de la métrica de Machado revela que efectivamente, a partir de un cuidadoso trabajo de la rima, la estrofa se convierte en la protagonista del libro: las agrupaciones de tres o cuatro versos, multiplicadas por las combinaciones de unos pocos metros, funcionan como verdaderas células sobre las que se erige la arquitectura musical del poema a partir de la ley de la variación. Pero los sutiles juegos y simetrías no empañan nunca la naturalidad del verso porque bajo la estrofa subyace con coherencia la verdadera clave de su construcción: el ritmo. Los diferentes ritmos del hexasílabo y el octosílabo se alternan y se cruzan en los poemas; para el endecasílabo basta el ritmo

\footnotetext{
${ }^{4}$ Navarro Tomás, Tomás: Los poetas en sus versos-Desde Jorge Manrique a García Lorca. Barcelona: Ariel, 1982, $1^{\text {a }}$ edición en Serie Studia, pp. 233-258.

${ }^{5}$ Ibid., p. 253
} 
del yámbico, si bien con un meticuloso entramado de acentos extrarrítmicos y antirrítmicos. En todos los casos el autor busca la oposición de las posiciones pares con las impares, como si de una suerte de contrapunto musical se tratara. Este aparente juego de alternancias se convierte así en la "ley" que da coherencia a todo el libro.

\section{Los versos}

Son pocos los metros utilizados por el autor en el libro. El libro suma sin grandes diferencias de tamaño aquella tradición que deriva del uso del endecasílabo en la forma culta de la silva $(11+7)$ y del soneto (que no es utilizado por Machado antes de este libro) junto a la que procede de la tradición popular, en la que aparece dominando el octosílabo y, en menor medida, el hexasílabo ${ }^{6}$. El arte mayor queda casi en exclusiva para los

$\overline{{ }^{6} \mathrm{He}}$ aquí la descripción de todos los poemas del libro, en la que evitamos a propósito mencionar nombres de estrofas, excepto en los casos en los que se usan sin modificaciones: CLIII -Olivo del camino: un poema en siete fragmentos, con endecasílabos (109 versos) y heptasílabos (16 versos). CLIV - Apuntes: nueve canciones que utilizan hexasílabos (59 versos) y octosílabos (2 versos). CLV -Hacia tierra baja: cinco canciones en decasílabos (15 versos), pentasílabos (4 versos), octosílabos ( 35 versos), tetrasílabos ( 2 versos) y hexasílabos (10 versos). CLVI -Galerías: un poema en siete fragmentos, con endecasílabos (42 versos) y heptasílabos (16 versos). CLVII -La luna, la sombra y el bufón: dos poemas en octosílabos (17 versos). CLVIII -Canciones de tierras altas: diez canciones en octosílabos ( 71 versos) y hexasílabos (37 versos). CLIX -Canciones: quince canciones que utilizan octosílabos (50 versos), hexasílabos (39 versos), heptasílabos (8 versos), tetrasílabos (1 verso), pentasílabo (1 verso) y decasílabos (1 verso). CLX -Canciones del alto Duero: seis seguidillas; heptasílabos (19 versos) y pentasílabos (23 versos). CLXI -Proverbios y cantares: noventa y nueve composiciones en octosílabos (246 versos), hexasílabos (70 versos), pentasílabos ( 8 versos), tetrasílabos (4 versos) y bisílabos (1 verso). CLXII -Parergon: un poema en tres fragmentos de versos endecasílabos (13 versos) y heptasílabos (6 versos). CLXIII - El viaje: un poema de octosílabos (13 versos). CLXIV-Glosando a Ronsard y otras rimas: 14 sonetos (I, II, III, IV, V, VI, VIII, XIV y XV) en endecasílabos (196 versos); una composición en tres fragmentos (VII) que utiliza octosílabos (53 versos), alejandrinos (11 versos) y tetrasílabos (5 versos); un poema (IX) en octosílabos (17 versos) y tetrasílabos (1 verso); 3 composiciones (X, XI y XII) que combinan endecasílabos (82 versos), heptasílabos (24 versos) y algunos irregulares (4 versos: dos alejandrinos, un tridecasílabo, un dodecasílabo, un eneasílabo); una composición (XIII) que incluyen ocho breves poemas que utilizan hexasílabos (27 versos) y octosílabos ( 6 versos); y una composición (XVI) que incluye siete breves poemas que utilizan octosílabos (26 versos) y hexasílabos (1 verso). CLXV-Sonetos: cinco sonetos en endecasílabos (70 versos). CLXVI -Viejas canciones: cuatro poemas que utilizan octosílabos (49 versos), hexasílabos (11 versos), decasílabos ( 2 versos), pentasílabos (1 verso), tridecasílabos ( 1 verso) y eneasílabos (1 verso). 
sonetos y para las varias y particulares combinaciones de endecasílabos y heptasílabos (silvas acosonantadas con elaboración muy particular y silvas romances). Un recuento de los versos nos permite ver:

\begin{tabular}{|c|c|c|c|}
\hline \multicolumn{4}{|c|}{ Versos: 1513} \\
\hline Bisílabos & 1 verso & Eneasílabos & 2 versos \\
\hline Tetrasílabos & 13 versos & Decasílabos & 18 versos \\
\hline Pentasílabos & 37 versos & Endecasílabos & 512 versos \\
\hline Hexasílabos & 254 versos & Dodecasílabos & 1 verso \\
\hline Heptasílabos & 89 versos & Tridecasílabos & 2 versos \\
\hline Octosílabos & 572 versos & Alejandrinos & 13 versos \\
\hline
\end{tabular}

Una vez descontados los usos ocasionales de versos compuestos, que pueden interpretarse como suma de grupos $(6+6$ y 7+6), queda claro que las irregularidades son muy pocas y que el autor se ha ido alejando mucho de los derroches y juegos modernistas (apenas usa en una composición el decasílabo, el eneasílabo modernista ha sido prácticamente abandonado, el alejandrino sólo aparece en el fragmento final de la poesía dedicada a Grandmontagne). Es evidente además, que el modo del pie quebrado va a estar muy presente en las composiciones: especialmente el heptasílabo como pie quebrado del endecasílabo; menos el tetrasílabo como pie quebrado del octosílabo. Parece ser así que la mezcla entre clasicismo y folclore de la que hablaba Macrí sí se da realmente en Nuevas canciones. La originalidad estriba en el tratamiento común que une ambos extremos, incluso a lo largo del dilatado periodo temporal en que el libro fue creándose: la depuración y la sencillez que el uso de tan pocos metros provoca en las composiciones. Machado no utiliza el verso libre, pero ha encontrado la libertad métrica en la tradición sencilla y en la fidelidad a las formas mencionadas. Esta ideología queda perfectamente expresada en los siguientes versos de De mi cartera (V) dentro del poema de XVI de CLXIV (Glosando a Ronsard y otras rimas): 
Verso libre, verso libre... Líbrate, mejor del verso cuando te esclavice.

\section{La estrofa: la ley de la variación}

La construcción que el autor hace en la combinación de los versos, en la estrofa, es un trabajo meticuloso que queda disimulado en la armonía del verso y la naturalidad que nos transmite, independientemente de que la búsqueda fuera premeditada o fluyera de un profundo arraigo del sentido del ritmo. ${ }^{7}$ La estrofa funciona en Nuevas canciones como verdadero centro de la composición, a modo de célula básica sobre la que se diseña el poema largo o sobre la que se construyen las agrupaciones de poemas breves y los distintos apartados que configuran el libro. Dentro de esa célula el autor busca la variación, la flexibilidad y la libertad (la fidelidad a unos pocos metros no le constriñe en absoluto) mediante las distintas combinaciones de los versos y de sus ritmos. Podemos resumir el juego estrófico en una "ley de la variación" que opera en distintos niveles a partir de la "estrofa-célula" que se toma como base:

1. Alteración.

1.1. Aumentada (versos de refuerzo).

1. 2. Disminuida.

1.2.1. Con verso más breve.

2. Multiplicación.

1.2.2. Con pie quebrado.

3. Contraste (con otra estrofa).

4. Alternancia.

La utilización de la terminología es intencionada; permite ver cómo la composición se levanta a modo de arquitectura musical, partiendo de un motivo normalmente breve (la estrofa) que crece

${ }^{7}$ Dice Navarro Tomás al comienzo de su trabajo: "En varias ocasiones, Machado declaró su preferencia por las formas métricas sobrias y sencillas. En los años de su juventud, la poesía modernista había invadido el campo del verso con audaces experiencias e invenciones. Sólo temporalmente, Machado adoptó algunas de aquellas novedades. Rehuyó todo lo que su ponderado juicio consideraba como artificioso o superfluo. Puso en cambio, con frecuencia, en la elaboración de sus versos, delicados efectos artísticos, no estudiados de propósito, sino nacidos de su hondo sentido del ritmo y armonía del idioma”. Ibid., p. 235. 
y se multiplica a partir de su variación. En un primer nivel, el del uso de agrupaciones de tres y cuatro versos, la estrofa puede alterarse bien aumentándose con un verso más de refuerzo (igual o distinto al de la base), bien por disminución (con un verso más breve que los que conforman la base o con su pie quebrado). A partir de aquí la combinación estrófica avanza ampliándose por multiplicación de la base (alterada o no), contrastando con otro grupo estrófico básico (en el que también se ha podido producir la alteración) o alternando las estrofas y sus variaciones en varias ocasiones.

Los medios para lograr la variedad que caben dentro de esta ley son muchos. En Olivo del camino la célula básica es el serventesio, dentro del cual se agrupan de forma libre y cambiante los versos endecasílabos y heptasílabos. En esa agrupación de versos de cuatro en cuatro, los heptasílabos funcionan como pie quebrado intermitente del endecasílabo (verso que aparece en el $77 \%$ de la composición frente al 13\% de los heptasílabos) y con variaciones importantes en cada fragmento del poema. Claro que la "célula 4 " es sometida a continua variación y cambio: a veces se suma al grupo de tres versos (terceto) para dar lugar a una séptima; a veces se le añade un verso más; a veces contrasta con un pareado; a veces los dos versos se unen para forma una sexta; en otra ocasiones aparece la célula doblada a modo de octava. La calificación de este poema como silva acosonantada no deja claro el juego de relaciones estróficas que el autor ha trabajado. Lo mismo ocurrirá con otros poemas del libro en los que también se utiliza lo que, en principio, debería ser llamado silva: en CLVI -Galerías se usa la silva-romance, con una estructura muy libre -esta vez sí- en la que el endecasílabo vuelve a ser el verso dominante. En CLXII - Parergon se utiliza la silva

${ }^{8}$ Ibid., p. 246: "El modo de silva acosonantada que Machado empleó no fue el del versos libremente trabados sin ninguna apariencia de orden estrófico, que venía siendo el modelo tradicional desde el Siglo de Oro, y que Darío, Unamuno y otros poetas modernos continuaron. La modalidad usada por Machado no tiene el verso como unidad básica, sino la estrofa, y consiste propiamente en una libre serie de pareados, tercetos, cuartetos y otros grupos de forma definida. Representa en realidad una disposición intermedia entre la poesía en estrofas uniformes y la de versos rimados sin orden alguno. Contra lo acostumbrado en la silva clásica, rara vez dejaba Machado en las suyas un verso sin rima. Otro poeta que por el mismo tiempo hizo uso de esta misma silva de estrofas mezcladas fue el mexicano González Martínez”. 
aconsonantada en su primer fragmento con la base del cuarteto y del cuarteto lira, para pasar a la silva romance en los fragmentos siguientes. También la silva romance se usa en CLXIV -Glosando a Ronsard y otras rimas en A Julio Castro (X) y Bodas de Francisco Romero (XII). Sin embargo en Flor de verbasco (XI) se utiliza de nuevo la silva aconsonantada que tiene como base el cuarteto lira y que algunas veces se une con la agrupación de tres versos del terceto. En todo caso, estos poemas son más breves que Olivo del camino, con el que se abre el libro y que marca, de alguna manera, el tono de los poemas en los que se utiliza el verso de arte mayor: la constante del juego estrófico se mantendrá siempre que aparezca la rima consonante, frente a la mayor libertad de la silva romance (con rima asonante).

Respecto a las estrofas que se utilizan cuando aparece el verso de arte menor, nos encontraremos con las agrupaciones básicas de versos en grupos de tres o de cuatro y con sus alteraciones y combinaciones. En CLIV Apuntes aparece por primera vez en el libro la célula de tres versos con rima asonante en los impares, en este caso en hexasílabos, por lo que se puede decir que esta célula es la de la soleariya, junto a la soleá para los versos octosílabos. Esta forma popular, la soleá, será importantísima en Nuevas canciones. En muchas ocasiones aparecerá agrupada con otras estrofas del mismo tipo, con diversos contrastes y variaciones de las rimas, por lo que hablaremos de tercetillos o tercerillos: preferimos, claro es, mantener el nombre de soleá para aquellas ocasiones en las que aparece como forma independiente, sola.

También a partir de Apuntes encontraremos las agrupaciones de versos en grupos de 4 (copla), con distintas combinaciones de versos (hexasílabos y octosílabos), y el romancillo, que, evidentemente, también utilizará la estructura de la cuarteta como base. En CLVII La luna, la sombra y el bufón aparece la redondilla de rima consonante, mientras que volveremos a encontrar la rima asonante en CLVIII Canciones de tierras altas (soleariya, copla, cuarteta, romance y romancillo). En general, en las Canciones son éstas las estructuras dominantes: soleares, soleariyas; pareados, tercetillos, coplas (en diversas agrupaciones); también agrupaciones de cuartetas y redondillas, o combinaciones de éstas con los grupos de dos y tres versos anteriores; quintillas en 
alguna ocasión, sextillas (suma de grupos de tres versos), septillas (suma del grupo de cuatro más tres o viceversa); romancillos y romances (que suelen partir del grupo de cuatro versos). Así ocurre en CLIX, CLXIII, CLIV (VII, IX, XIII, XVI) y CLXVI. En las Canciones, como en Proverbios y cantares, la flexibilidad que el juego de combinaciones y variaciones sobre las células básicas (grupos de tres y cuatro versos) vuelca sobre la estrofa se refuerza con la combinación de los tipos de verso dentro de ellas, normalmente los octosílabos y los hexasílabos.

Mencionamos ahora aquellos casos que, por lo ocasional, llaman la atención dentro del libro. Así en CLV Hacia tierra baja encontramos el poema I "Rejas de hierro; rosas de grana" que está compuesto en versos decasílabos compuestos (polirrítmicos, yámbicos y adónicos) que se combinan en tres ocasiones con el verso pentasílabo: es evidente que la célula del verso de cinco sílabas es casi una excepción en el libro, aunque dentro del poema se agrupa, como de costumbre, en grupos de cuatro y tres versos, con una cuidadosa utilización de la rima consonante (con versos reforzados, de enlace y de vuelta que se suman a los grupos básicos para dar lugar al quinteto, por ejemplo). Destacan también especialmente las seguidillas de CLX Canciones del alto Duero. Machado elige para estas canciones la seguidilla compuesta (la primera parte 7-5a 7-5a, con rima asonante; la segunda, el estribillo, con la estructura 5b7-5b, con rima asonante). Puesto que es ésta una estructura muy cerrada, apenas hace Machado cambios sobre ella y, de las seis seguidillas, sólo establece una pequeña variación en la primera, donde el último verso es heptasílabo en lugar de pentasílabo. Fuera de las seguidillas no es usual el heptasílabo en las canciones -parece reservado para el pie quebrado del endecasílabo y la rima consonante correspondiente, dentro de los poemas de arte mayor. Es reseñable el heptasílabo que aparece en el poema XV de CLIX -Canciones "Mientras danzáis en corro", donde la rima asonante en lo versos pares nos hace pensar en la estructura del romance, si bien ciertas repeticiones rememoran evidentemente las estructuras de la propia canción, con estribillo, glosa y versos de vuelta. Finalmente, el uso de los versos alejandrinos se hace en el fragmento III del poema dedicado a Grandmontagne (CLXIV, VII), donde destaca por su contraste con los dos anteriores fragmentos: 
pasamos de la base octosílaba (distribuida en cuartetas, redondillas, sextillas, quintillas y pareados) al verso compuesto (de ritmo mantenido, todos los alejandrinos son yámbicos) repartido en pareados y en un terceto. Eso sí, los tres fragmentos mantienen el mismo tipo de rima, la consonante.

En cuanto a la rima, es evidente que Machado le presta gran atención puesto que el trabajo en la elaboración de la estrofa depende de ella. Machado deja versos sin rimar cuando utiliza las estructuras de romance, romancillo y la silva de romance. Lo mismo ocurre cuando aparecen la copla o cantar y, por supuesto, la soleá y la soleariya: son todas estrofas muy queridas por el autor que se apoyan en la rima asonante ${ }^{9}$. Pero eso no quiere decir que ésta sea el único tipo de rima ni que éstas sean las estrofas que más aparecen en el cómputo del libro. Del mismo modo que los endecasílabos que aparecen en las silvas de romance tienen rima asonante, en los poemas breves también podemos encontrar la rima consonante en el verso de arte menor. La conclusión es que la rima preferida es la sencilla, y ésta puede serlo tanto consonante como asonante. No olvidemos que Machado parece jugar siempre con la variación y el cambio, y ello deriva de una íntima concepción del ritmo. La rima no es ajena a esa variación. El análisis muestra los numerosos juegos que se producen con las rimas: casos en los que aparecen rimas internas, alternancias en el uso de las vocales que se utilizan, mínimos cambios en esas vocales que, sin embargo, generan de una forma natural expresivas sonoridades o palabras en las que los dos tipos de rima son muy cercanos. Finalmente hay que mencionar el escaso uso de la rima en palabras esdrújulas, mientras que son abundantes las de la palabra llana y -como un rasgo de estilo-también las rimas que Machado busca en palabras agudas (tanto asonantes como

${ }^{9}$ Al respecto dice Navarro Tomás, T. Ibid., p. 248: "En el fondo, no obstante su evidente dominio de la rima consonante, Machado sintió siempre decidida predilección por la asonancia. La causa de esa inclinación era sin duda el constante propósito de Machado de evitar todo lo que pudiera tener apariencia de artificio". En Nuevas canciones existe una poética del autor sobre el tema (CLXIV, XVI, De mi cartera):"V Prefiere la rima pobre,/la asonancia indefinida./Cuando nada cuenta el canto,/acaso huelga la rima".Y más adelante: "VII La rima verbal y pobre,/ y temporal, es la rica./El adjetivo y el nombre/remansos del agua limpia,/ son accidentes del verbo/en la gramática lírica,/del Hoy que será Mañana,/del Ayer que es Todavía". 
consonantes). La naturalidad y sencillez del vocabulario poético de Machado se corresponden con la fluidez de la rima.

\section{Un ejemplo: Proverbios y cantares (CLXI)}

CLXI -Proverbios y cantares es, por supuesto, el apartado del libro donde más composiciones breves aparecen. Aquí encontramos las agrupaciones de versos en grupos de tres y cuatro que también se dan antes de CLXI y que seguirán después en las Canciones, si bien con más casos en los que la agrupación se hace de forma independiente. Como en las Canciones, también en Proverbios y cantares las estrofas combinarán dentro de ellas los distintos tipos de verso breve. El octosílabo es el verso más utilizado, seguido por el hexasílabo y, en alguna ocasión, el pentasílabo. Las combinaciones de estos versos en estrofas son variadas, aunque prevalece la soleá. Le siguen las coplas y las redondillas. Los romances parten de la agrupación de cuatro versos. Las combinaciones que aparecen en los esquemas siguientes son válidas también para otras composiciones del libro: Apuntes, Canciones de tierras altas, las Canciones de CLIX, El viaje, Soledades a un maestro y De mi cartera. Además, en Proverbios $y$ cantares varios de los poemitas son independientes pero se relacionan temáticamente con los que les siguen para establecer una oposición en el sentido, un contraste, una matización o un añadido (las agrupaciones no superan los dos o tres poemas y, en algunas ocasiones, también se marcan mediante rimas que se encadenan) ${ }^{10}$. Tampoco faltará el fenómeno inverso: en los poemas LXV y LXXXVII aparecen tres soleares en cada uno. Y esta vez sí que las llamamos soleares y no tercetillos para demostrar que la soleá es la célula básica y que, en efecto, también cada una de ellas podría leerse de forma independiente y con sentido (el sentido proverbial y filosófico de este apartado). Hacemos a continuación un recuento, a modo de ejemplo, de todas las combinaciones que se producen en los casos de rima asonante, que son los más representativos de este apartado del libro ${ }^{11}$ :

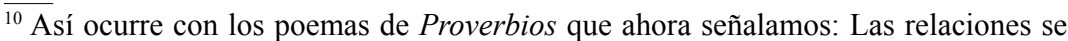
dan entre: III-IV, VII-VIII, XIX-XX-XXI, XIV-XV, XXVIII-XXIX-XXX, XXXI -XXXII-XXXIII, XXXVII-XXXVIII, XLII-XLIII-XLIV, LXXI-LXXII, LXXXVIII-LXXXIX, XCI-XCII, XCIV-XCV, XCVI-XCVII.

${ }^{11}$ En el caso de las combinaciones de versos con rima consonante en Proverbios $y$ 


\begin{tabular}{|c|c|c|c|}
\hline \multicolumn{4}{|c|}{ Proverbios y cantares - Con rima asonante } \\
\hline \multicolumn{4}{|c|}{ Estrofas de tres versos } \\
\hline $\begin{array}{c}\text { Combinación de } \\
\text { versos }\end{array}$ & Poemas & $\begin{array}{c}\text { Combinación de } \\
\text { versos }\end{array}$ & Poemas \\
\hline $8,8,8$ Soleá & $\begin{array}{l}\text { I, XII, XIII, XX, XIV, XXV, } \\
\text { XXX, XXXII, XXXIX, } \\
\text { XLI, XIIV, XLV, XI VII, } \\
\text { LIV, LVI, LX, LXII, LXXVI, } \\
\text { LXXVII, LXXX, } \\
\text { LXXXVII(1), LVXXXVII(2), } \\
\text { LXXXVII, LXXXIX, XCI, } \\
\text { XCII }\end{array}$ & $6,6,6$ Soleariya & $\begin{array}{l}\text { II, III, XXII, XXVII, XXIX, } \\
\text { LIX, LXI, XCVIII }\end{array}$ \\
\hline $6,8,6$ & LV, LXX & $8,6,6$ & LXIII, XCVI, XCVII \\
\hline $8,8,6$ & V, L, LVIII, XC & $5,6,5$ & LXV \\
\hline $6,8,8$ & VI, XXII, XLIII, LI, (LXV) & $8,8,5$ & LXIX \\
\hline $6,6,5$ & xxvI & $8,8,(3 / 4)$ & LXXI \\
\hline $6,6,8$ & XXXI, (LXV) & $8,8,2$ & LXXXIV \\
\hline $8,5,(7 / 8)$ & XLVIII & & \\
\hline \multicolumn{4}{|c|}{ Estrofas de cuatro versos } \\
\hline Copla octosílaba & XVIII, XIX, LVII, LXXIV & $\begin{array}{l}\text { Copla de base } \\
\text { octosílaba con un } \\
\text { hexasílabo }\end{array}$ & XXXIV \\
\hline $\begin{array}{c}\text { Copla de base } \\
\text { octosílaba con dos } \\
\text { hexasílabos }\end{array}$ & LXXIII, LXXV & Copla hexasilaba & LXXXVI \\
\hline \multicolumn{4}{|c|}{ Romances } \\
\hline $\begin{array}{c}8,8,8,(5 / 6) \\
8,8,8,6 \\
8,8\end{array}$ & LXIV & $\begin{array}{l}8,8,8,8 \\
8,8,8,8\end{array}$ & LXXIX \\
\hline $\begin{array}{l}8,8,8,8 \\
8,8,8,8 \\
8,8,8,8\end{array}$ & LXXXIII & $\begin{array}{c}8,5,8,8 \\
8,8\end{array}$ & $\mathrm{XCIII}$ \\
\hline
\end{tabular}

cantares encontramos idénticas variaciones a partir de los tres versos de la soleá. Además aparecen pareados, coplas hexasílabas, redondillas $a b b a$, una redondilla a la que suma un pentasílabo (XL), cuartetas $a b a b$, y estrofas de cinco versos (o quintillas) que se forman sumando un verso a una redondilla (X) o dejando un verso suelto (VIII) que, a su vez, forma una quintilla con VII. 


\section{El ritmo: la ley del contrapunto}

Si la variación y el contraste, los matices, aparecen como resultado de las combinaciones de los versos, de sus rimas y de sus combinaciones estróficas, es en el ritmo versal donde encontramos la raíz íntima de toda esa riqueza que se erige -como hemos dicho- a pesar de la reducción de metros y del uso de las mínimas estructuras (células) de las que parte todo el juego de la composición. Ahora vemos cómo la ley de la variación tiene su raíz íntima en la ley del contrapunto rítmico, que se produce así:

1. Uso de versos polirrítmicos

2. Cambio constante de ritmo

3. Contraste dentro de un mismo ritmo: acentos extrarrítmicos y antirrítmicos

4. Contraste entre posiciones pares-impares:

4.1. Sílabas $1^{\mathrm{a}}-2^{\mathrm{a}} / 3^{\mathrm{a}}-\left(4^{\mathrm{a}}\right)-5^{\mathrm{a}}$ (verso breve)

4.2. Sílabas $1^{\mathrm{a}}-\left(2^{\mathrm{a}}\right)-3^{\mathrm{a}} / 3^{\mathrm{a}}-\left(4^{\mathrm{a}}\right)-5^{\mathrm{a}} / 6^{\mathrm{a}}-7^{\mathrm{a}}$ (endecasílabo)

En el fondo eso es la armonía, que el autor consigue por la suma y superposición de elementos siempre de forma coherente, como arquitectura musical que se levanta en sucesivas capas y suma acordes en torno al del ritmo del verso y la melodía de la palabra. De alguna manera esa construcción musical nos recuerda a la de la música popular y a la del cante jondo, con las que también se identifica la obra de Machado. Especialmente en el último caso, donde el cante llega a una extraordinaria complicación de los elementos que en apariencia son sencillos. Pero también recuerda a esa difícil sencillez, difícil naturalidad que tiene toda obra verdaderamente popular, sea cante, canción o jota. El ritmo de verso en Machado busca siempre el movimiento, la variación, el contraste. Si habláramos de música deberíamos mencionar una suerte de contrapunto, de oposición entre ritmo y contrarritmo, de contraste entre los movimientos fuertes y débiles del compás, que en el verso equivalen a las oposiciones entre sílabas tónicas, sílabas átonas y la alternancia entre los lugares que ambas ocupan dentro del verso. 
Muy raramente veremos el mismo ritmo mantenido a lo largo de varios versos: se trata de evitar la monotonía mediante el cambio continuo del ritmo, entre unos pocos versos o incluso de un verso a otro. El autor buscará el contraste entre las posiciones acentuadas, a veces con mínimos añadidos de acentos extrarrítmicos, a veces simplemente añadiendo o quitando acentos respecto al verso anterior (aunque sea dentro de un mismo esquema acentual) al cambiar de metro y, en general, con el uso del verso polirrítmico en la composición. Al igual que en la escala musical es el juego entre la natural y sus alteraciones lo que produce el color de la composición, o como en el flamenco es la distancia del semitono la que rompe la escala y genera la fuerza del cante, también Machado rompe constantemente la estructura rítmica de un verso en el siguiente. Pero lo hace sin estridencias y sin perder la naturalidad del ritmo: he ahí su coherencia. Lamentablemente no tenemos registros grabados por el autor de sus poemas ${ }^{12}$. Y el estudioso debe tener mucho cuidado para no interpretar -o sobre interpretar- erróneamente la obra, limitándose a aquellos elementos sobre los que no cabe duda, pero es manifiesto que los contrastes rítmicos son solidarios con los que se producen en otro nivel combinando los tipos de versos y combinando las agrupaciones estróficas dentro de una misma composición.

Machado utiliza el hexasílabo anfibráquico (acentos en $2^{\mathrm{a}} \mathrm{y}$ $5^{\mathrm{a}}$ ) junto al trocaico (acentos en $1^{\mathrm{a}}, 3^{\mathrm{a}}$ y $5^{\mathrm{a}}$ ). Las composiciones sólo en hexasílabos son evidentemente polirrítmicas: domina el verso trocaico, que llega al $60 \%$ de los usos. El anfibráquico supone un poco más del $34 \%$, mientras que hay un $5 \%$ de casos en los que la lectura del verso resulta dudosa y son los apoyos secundarios los que pueden decidirnos en uno o en otro sentido. En todo caso, la alternancia de ritmos dentro del poema supone el contraste continuo entre la posición 2 (anfibráquico) y las posiciones 1, 3 (trocaico). Especialmente el contraste entre la sílaba $1^{\mathrm{a}}$ y la $2^{\mathrm{a}}$ parece un rasgo de estilo del autor, que se puede aplicar casi a todas las composiciones y a todos los tipos de verso que

\footnotetext{
${ }^{12}$ Navarro Tomás explica con detalle sus intentos para que Machado procediera a la grabación de alguna lectura de sus poemas, grabación que no llegó a realizarse. NAVArro TomÁs, T.: Ibid, pp. 257- 258.
} 
maneja, incluidos los largos. Cuando no se produce este contraste, y el ritmo se mantiene a lo largo de varios versos, es cuando aparece el cambio de tipo de verso (más largo o más corto), que es un contraste importante, aunque no se cambie forzosamente el ritmo: por ejemplo, podemos combinar hexasílabos trocaicos con octosílabos trocaicos. En el caso del octosílabo -que es el verso breve más utilizado por el autor- nos encontramos con estos ritmos:
a) octosílabo dactílico $(1,4,7)$ :
$17,3 \%$
b) octosílabo trocaico $(1,3,5,7)$ :
$32,5 \%$
c) octosílabo mixto $(2,4 / 5,7)$ :
$37,6 \%$
d) octosílabos dactílicos o mixtos:
$8,6 \%$
e) casos dudosos:
$4 \%$

Otra vez, claro está, el poema en octosílabos es polirrítmico. Y de nuevo encontramos la tendencia a variar el tipo de octosílabo no más allá de los tres o cuatro versos como mucho, estableciendo oposiciones y contrastes entre las posiciones impares del trocaico con las pares del dactílico (acento en $4^{\mathrm{a}}$ ) y del mixto (acento en $2^{\mathrm{a}}$ ). De nuevo, como en el caso del hexasílabo, la sílaba $1^{\mathrm{a}}$ aparece como contrapunto de la $2^{\mathrm{a}}$ y la $3^{\mathrm{a}}$ de la $4^{\mathrm{a}}$. Si las primeras secciones del libro tienen al octosílabo trocaico como protagonista, el mixto va imponiéndose según avanzamos, y es el ritmo que más aparece en Proverbios y cantares. Puesto que aquí los poemas son muy breves, cuando este verso no se combina con los ritmos del hexasílabo, basta un leve cambio en el ritmo del mixto (acentuar en $4^{\mathrm{a}}$ o $5^{\mathrm{a}}$ ) para establecer el contraste par/impar. Cuando se vuelve a las canciones, vuelve a dominar el trocaico, dando lugar a otras combinaciones y otras alternancias -a veces verdaderamente simétricas-. El autor es fiel a su ideología de creación: sencillez, pocos elementos para un rendimiento extraordinario.

Cuando aparece el pentasílabo suele hacerlo como adónico $(1,4)$ y en menos ocasiones como yámbico $(2,4)$; los decasílabos -como ya vimos- son polirrítmicos, por lo que responden a las combinaciones anteriores de los pentasílabos en cada hemistiquio. El uso del eneasílabo es testimonial (eneasílabo mixto, 3, 
$5,8)$. El uso del heptasílabo lo veremos unido al endecasílabo en las silvas. Cuando aparece en las canciones -muy poco- suele hacerlo como yámbico $(2,4,6)$ y escasamente como mixto $(1,4$, $6)$, pero en las seguidillas prácticamente lo hace como anapéstico $(3,6)$ : es uno de los pocos casos en los que si hay dudas la lectura del verso se resolverá hacia este ritmo por la influencia de los demás.

En definitiva, basta multiplicar los tipos de versos que se combinan por sus ritmos para darnos cuenta de las muchísimas posibilidades de los contrastes rítmicos que se producen en los poemas, sobre todo en las canciones y en los proverbios, y que dan lugar a curiosas simetrías y alternancias. El contraste en los acentos entre la sílaba $1^{\mathrm{a}}$ y la $2^{\mathrm{a}}$ es un rasgo de estilo que el autor aplica casi a todas las composiciones y a todos los tipos de verso que maneja. En general, podemos concluir que en los versos de Machado existe la búsqueda constante de un contrapunto rítmico, como una suerte de composición musical en la que subyace tanto la esencia de la canción popular como la esencia del flamenco y del cante jondo, que conoció bien el autor. En un primer nivel el contrapunto rítmico par/impar marca el compás del verso (con sus variaciones de movimientos fuertes y débiles); éste, a su vez, se armoniza en un segundo nivel con la melodía del verso (cómputo silábico y rima) -donde aparecen de nuevo la variedad y el contraste-; y ambos niveles se armonizan en un tercero: el del acorde musical, el de la estrofa, que sirve para erigir finalmente el poema a partir de la alternancia y la combinación, sin estridencias y sin perder la naturalidad del ritmo ${ }^{13}$.

${ }^{13}$ En el estudio métrico de los versos de Nuevas canciones hay que tener en cuenta algunas particularidades, especialmente las que se producen con algunas palabras que prosódicamente son tónicas pero que se usan como átonas en el libro, caso de monosílabos como los adverbios "no" y "ya", el indefinido "un" y los auxiliares verbales "ha" y "he" del verbo haber utilizados en las forma compuestas. En muchas ocasiones estas formas aparecen dentro de sinalefa y dando lugar a lo que podría ser un acento antirrítmico o bien a la desacentuación de la sílaba. No es extraño que la concurrencia de dos posiciones tónicas en un verso (óó) se resuelva en la lectura real mediante la preeminencia de una de las dos (óo/oó) dependiendo del contexto métrico. Cuando esta situación se produce nos inclinaremos por suponer que son esos monosílabos dentro de sinalefa los que "ceden" la tonicidad a favor de la otra sílaba acentuada: una sílaba que posiblemente pertenezca a un sustantivo o un adjetivo o a una forma verbal no auxiliar. El mismo comentario es válido para los casos en los que el verbo "es” y la interjección “¡Oh!” también 
Este contrapunto es, por lo tanto, la raíz que genera la variedad del libro: lo mismo que en la música es el juego entre la escala natural y sus alteraciones lo que produce el color de la composición; lo mismo que en el flamenco es la distancia del semitono frente al tono la que rompe la escala y genera la fuerza del cante.

\section{El endecasílabo. Los sonetos}

Además de en las silvas (acosonantadas y romances), combinado con el heptasílabo, Machado utiliza el endecasílabo en los sonetos. Nuevas canciones es el libro donde aparece por primera vez de forma sistemática el soneto, lo que no deja de ser un hecho sorprendente y nos permite ver la evolución de Machado en sus usos métricos y su distancia hacia las formas modernistas. Es de suponer, por tanto, que Machado trata de encontrar en el soneto un equilibrio entre la solidez y la ligereza, un camino en el que la estructura no le ate y le permita -no es paradójico- la libertad que encuentra en la composición breve de estilo popular. $\mathrm{O}$, lo que es lo mismo, el soneto debe servirle para producir sin estridencias la conjunción de clasicismo y folclore a la que hemos aludido al principio del estudio. El hecho de que el autor, en Nuevas canciones, se siente satisfecho de los resultados queda demostrado por el uso del soneto: soneto que no sólo estará dedicado ocasionalmente a la glosa de aquellos a quienes admira y homenajea, sino dedicado también a plasmar el recuerdo íntimo de momentos esenciales para el lirismo machadiano: así en CLXIV-[XVI] -Los sueños dialogados; o en CLXV -Sonetos[IV], que dedica a su padre.

Tampoco es paradójico que el endecasílabo de Machado sea siempre el yámbico. El análisis muestra que sólo forzando la lectura podríamos encontrar el endecasílabo anapéstico (4, 7, 10) y el de gaita gallega $(1,4,7,10)$ en un par de ocasiones a

aparece dentro de sinalefa. En el fondo lo que parece ocurrir con estos monosílabos es que su aparición dentro de sinalefa alarga la sílaba en la que se encuentran, de modo que esa mayor duración compensa la perdida de tonicidad, que así se desvía con claridad hacia la sílaba próxima. En este sentido, sería interesante que las ediciones de su obra incluyeran también notas sobre estos aspectos y sobre otras particularidades que han pasado desapercibidas: rupturas de sinalefas que indiscutiblemente deben realizarse de acuerdo al análisis métrico, varios desplazamientos de acentos y algunas sinéresis y diéresis que no se han señalado convenientemente. 
lo largo del libro. Este uso del endecasílabo yámbico vale para los sonetos y también para todos los endecasílabos de las silvas del libro. No quiere esto decir que se rompa en estos versos la ley de la variación. Una de esas variaciones se da a través de la combinación del verso endecasílabo con el heptasílabo en las silvas, pero el soneto es una estructura cerrada que, por tanto, requiere otro tratamiento. El primero de los juegos de variaciones -o el más aparente-se da nuevamente con la estrofa y la rima de los sonetos. Aquí las rupturas no pueden ser muchas. Pero, aunque el autor evita los extremos modernistas - no abandona el endecasílabo, por ejemplo-sí se permite algunas alteraciones de estilo muy personal. De este modo va a jugar con la combinación de serventesio (rima cruzada) y cuarteto (rima abrazada). La forma que más utiliza (en doce ocasiones) es la de sumar dos serventesios de rimas independientes en cada a estrofa a dos tercetos al modo clásico: ABAB CDCD EFE FEF (o bien tercetos EFG EFG). El soneto clásico sólo aparece en cuatro ocasiones: ABBA ABBA CDC DCD y aun así puede cambiarse dentro de él el cuarteto por el serventesio. En algunas ocasiones los tercetos juegan a repetir una de las rimas de los cuartetos o bien a establecer una rima muy particular: EFF EFF. Un caso realmente curioso se produce en el IV soneto de CLXV -Sonetos, cuya estructura suma un cuarteto, un serventesio y dos tercetos ABBA CDCD EEF GFG.

Pero aparte de estos juegos de combinaciones estróficas la verdadera clave de la integración armoniosa del soneto en el libro Nuevas canciones radica de nuevo en la variación rítmica del verso, variación que el endecasílabo yámbico le permite al autor $^{14}$. En las combinaciones distinguimos los endecasílabos yámbicos a maiori de los yámbicos a minori, y señalamos especialmente los casos en que aparecen acentos extrarrítmicos y antirrítmicos. Aunque las interpretaciones de los porcentajes pueden ser diversas -hay agrupaciones de tantos por ciento que no se indican-, los valores generales muestran las tendencias rítmicas claramente. Los porcentajes dentro de cada uno de los grupos básicos dejan constancia de las combinaciones más usadas en cada uno.

${ }^{14}$ Ver el cuadro final. 
Los endecasílabos sin extrarrítmicos son aproximadamente la mitad de todos (48\%), de los que a su vez los heroicos doblan a los sáficos. El uso de los acentos extrarrítmicos va a ser notable, y es ahí donde volvemos a encontrar la clave del contraste y de la alternancia entre posiciones par/impar, de manera idéntica a lo que ocurría en el verso breve. Los acentos extrarrítmicos se dan, por orden de mayor a menor uso, en $3^{a}$ sílaba, $1^{a}$ sílaba y en $1^{\mathrm{a}}$ y $3^{\mathrm{a}}$ a la vez. Llegan a suponer el $38 \%$ de todos los versos, con dominio esta vez más acentuado de los heroicos sobre los sáficos. Finalmente los acentos antirrítmicos aparecen en el 14\% de los endecasílabos, por lo que es evidente que también en ellos encontramos una verdadera voluntad rítmica del autor. Hay que aclarar que los acentos antirrítmicos son considerados aquí sólo cuando pueden ser marcados con claridad ${ }^{15}$. Hay así acentos antirrítmicos sobre las sílabas $1^{\mathrm{a}}, 3^{\mathrm{a}}, 5^{\mathrm{a}}$ y $9^{\mathrm{a}}$, no más de uno por verso (algunas veces dos) y siempre de forma un tanto ocasional en el poema, pero que suman un porcentaje no despreciable si tenemos en cuenta el cómputo de todos los sonetos. Muy interesantes son los acentos antirrítmicos menos ocasionales, que son los que aparecen sobre la $7^{\mathrm{a}}$ sílaba. Hay bastantes versos en los que concurren a la vez acentos en $6^{\mathrm{a}}$ y $7^{\mathrm{a}}$, siendo los de $6^{\mathrm{a}}$ uno de los ejes rítmicos del verso yámbico en todo el conjunto del poema. En esos casos el autor ha hecho recaer también un acento indiscutible sobre la $7^{\mathrm{a}}$ sílaba, puesto que se sitúa sobre palabra de indiscutible tonicidad que, además, puede venir separada gráficamente de la $6^{\mathrm{a}}$ sílaba en el poema mediante coma u otro signo de puntuación entre las dos palabras: nueva muestra de la voluntad de estilo en el contrapunto ${ }^{16}$.

\section{Conclusión}

El análisis métrico de Nuevas canciones revela así complejos y sutiles juegos estructurales en todos los niveles del estudio. Más allá de buscar simetrías extravagantes, se demuestra que el autor ha interiorizado un sentido del ritmo que le permite dar

$\overline{15}$ Véase la nota 12.

${ }^{16}$ Buenos ejemplos de ello encontramos en los versos 9 y 13 de CLXIV-[XII] -Los sueños dialogados; en los versos 3 y 10 del soneto III y en los versos 3 y 11 del soneto V (en CLXV-Sonetos); y también en los versos 22 y 32 de CLXIV-[X]-A Julio Castro, por poner el ejemplo de una silva. 
extraordinaria variedad y flexibilidad a los pocos elementos que forman su paleta métrica. El análisis métrico de Nuevas canciones pone de relieve que es en este nivel de estudio donde más claramente se percibe la unidad del libro y que el título es el denominador común para lo que de otra manera sólo sería mezcla heterogénea de los temas machadianos: recuerdo, soledad, la confesión íntima, sueño, paisaje, elogio, aforismo, Proverbio $y$ cantar. Por el contrario, es en la métrica donde subyacen las claves que, a partir de la ley de variedad estrófica y la ley del contrapunto rítmico, confieren unidad a una poética que es también ética: la depuración de elementos, la riqueza de lo sencillo, la libertad expresiva que late en la forma tradicional, la vena inagotable del ritmo que enlaza lo clásico con lo popular y que pervive en la verdadera poesía, la poesía que hace el pueblo. 


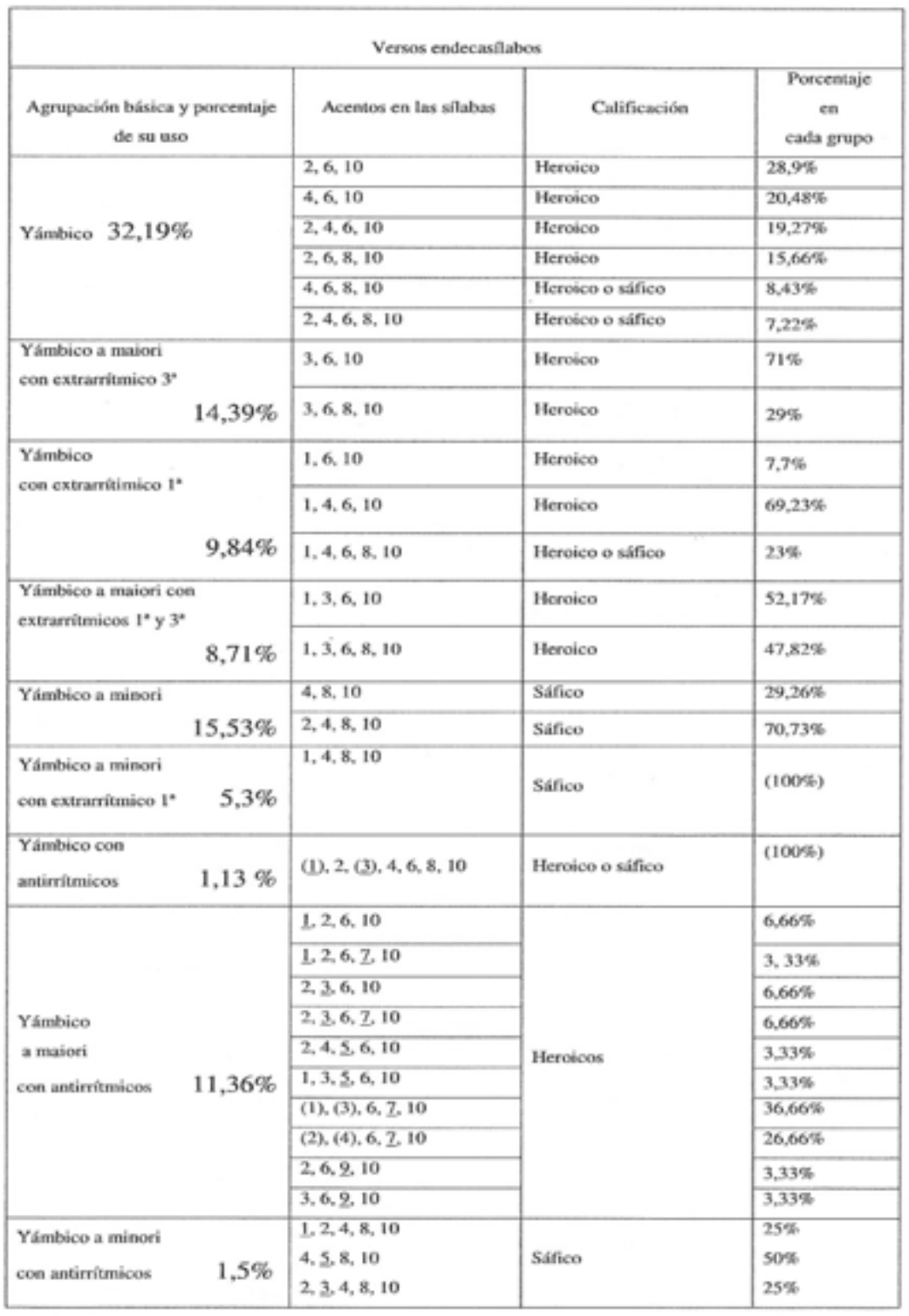

Cuadro: ritmo de los endecasílabos en los sonetos de Nuevas canciones 


\section{Bibliografía utilizada}

ALVAR, M.: (1975) edición de Antonio Machado: Poesía completa. Madrid: Espasa Calpe, Colección Austral, 2009, $48^{\circ}$ edición.

DOMINGUEZ CAPARRÓS, J.: (2000) Métrica española. Madrid: Síntesis, $2^{\mathrm{a}}$ edición revisada.

-(2001) Diccionario de métrica española. Madrid: Alianza Editorial, $2007,2^{\mathrm{a}}$ reimpresión.

-(2005) Elementos de métrica española. Valencia: Tirant lo Blanch.

-(2009) El moderno endecasílabo dactílico, anapéstico o de gaita gallega. Sevilla: Padilla Libros, Rhythmica Revista Española de Métrica Comparada, Anejo III.

GIL, A.: (1998) Introducción a Cantes flamencos recogidos y anotados por Antonio Machado y Álvarez (Demófilo). Barcelona: DVD Ediciones, Los cinco elementos.

MACRÍ, O.: (1989) edición de Antonio Machado, Poesía y prosa, dos volúmenes. Madrid: Espasa-Calpe, Clásicos castellanos.

NAVARRO TOMÁS, T.: (1956) Métrica española. Reseña histórica y descriptiva. Madrid: Guadarrama, 1972, tercera edición corregida y aumentada.

-(1968) Manual de pronunciación española. Madrid: CSIC, $14^{\mathrm{a}}$ edición.

- (1973) Los poetas en sus versos. Desde Jorge Manrique a García Lorca. Barcelona: Ariel, primera edición en Serie Studia, 1982. 